\title{
MOCVD of $\mathrm{ZrO}_{2}$ films from bis(t-butyl-3-oxo-butanoato)zirconium(IV): some theoretical (thermodynamic) and experimental aspects
}

\author{
SUKANYA DHAR*, M S DHARMAPRAKASH and S A SHIVASHANKAR \\ Materials Research Centre, Indian Institute of Science, Bangalore 560 012, India
}

MS received 8 August 2007

\begin{abstract}
The equilibrium concentrations of various condensed and gaseous phases were calculated from thermodynamic modeling of MOCVD of $\mathrm{ZrO}_{2}$ films using a $\beta$-ketoesterate complex of zirconium as precursor. This leads to the construction of the 'CVD phase stability diagram' for the formation of solid phases. In the reactive ambient of oxygen, the calculations predict carbon-free $\mathrm{ZrO}_{2}$ film over a wide range of process conditions. The thermodynamic yields are in reasonable agreement with experimental observations, though the removal of carbon from the MOCVD grown films is not as complete as the thermodynamic calculations predict.
\end{abstract}

Keywords. MOCVD; $\mathrm{ZrO}_{2}$ films; CVD phase stability diagrams.

\section{Introduction}

Due to the excellent thermal and mechanical stability, optical and electrical properties of zirconia, thin films of zirconia have important optical, dielectric, corrosion protection, electrochemical and sensor applications (Lin et al 2006; Li et al 2007). Chemical vapour deposition (CVD) is one of the primary methods for the fabrication of zirconia films. In the CVD of $\mathrm{ZrO}_{2}$, the choice of precursors, together with the process parameters, determines the microstructure and related properties of the films. Thermodynamic analysis can be used to calculate the equilibrium concentrations of various condensed and gaseous phases in a CVD process, as functions of different experimental parameters for a given chemical precursor (Bernard et al 1999). These theoretical observations help in selecting the optimum operating conditions as well as in predicting the possible impurities (or undesired phases) in the deposited films. In thermodynamic modeling, calculations are performed under the assumption that equilibrium is reached in the system. Although equilibrium does not necessarily prevail in a CVD process, such an approach can give fundamental information that enhances the understanding of the process, and has been found helpful in the metalorganic CVD (MOCVD) of GaAs and several other systems (Stringfellow 1989; Bernard et al 1999; Kang et al 2000). The modeling is based on the minimization of the total Gibbs free energy of the system, obeying the mass balance conditions (Eriksson 1971). Though there may be some quantitative uncertainty in the predictions made by such analysis, they are usually accurate

*Author for correspondence (sukanya@mrc.iisc.ernet.in) enough to guide MOCVD process development (Stringfellow 1989). A considerable amount of experimental work has been reported on the effect of processing conditions on the purity, morphology, and growth rate of $\mathrm{ZrO}_{2}$ thin films grown by MOCVD (Dharmaprakash and Shivashankar 2003a, b; Pasko et al 2004; Huang and Wu 2004; Patil et al 2006). However, to our knowledge, there has been no report of a detailed thermodynamic analysis on the MOCVD of $\mathrm{ZrO}_{2}$ films aimed at predicting the effect of processing conditions on the deposition.

A $\beta$-ketoesterate complex, viz. bis(t-butyl-3-oxo-butanoato)zirconium(IV), abbreviated as $\mathrm{Zr}$ (tbob) ${ }_{4}$, was used in the present study as a precursor, because of the enhanced volatility caused by the oxygen atom in the terminal group of this subliming solid (figure 1(a)). Equilibrium compositions of the solid and gaseous species formed during the MOCVD of $\mathrm{ZrO}_{2}$ using this precursor were calculated, and the corresponding 'CVD phase stability diagram' for the formation of the solid phases constructed. MOCVD runs were carried out using this precursor and process parameters in ranges suggested by the modeling. The as-grown films were characterized for the identification of the crystalline phases, and for elemental composition.

\section{Procedure}

\subsection{Analytical}

The method of equilibrium thermodynamic analysis of a MOCVD process is based on the minimization of the total Gibbs free energy of the system considered, satisfying the mass balance conditions (Eriksson 1971). The approach 
requires the identification of all the possible reactants and reaction products. Where experimental data (e.g. through in situ mass spectrometry) to identify all the gaseous species present in the CVD chamber are not available, an informed and careful enumeration of the species that can result from the CVD process is an important step in thermodynamic modeling.

The starting point is the mass spectrum (figure 1(b)) of the precursor which, together with 'chemical reasoning', may be employed to enumerate the gaseous species to be considered in the modeling. Fragments of higher molecular weight were not included in the calculations, as they are expected to undergo further fragmentation to produce $\mathrm{CHCO}$ with $\mathrm{m} / \mathrm{z}=41, \mathrm{CH}_{3} \mathrm{CO}$ with $\mathrm{m} / \mathrm{z}=43$, and $\mathrm{C}\left(\mathrm{CH}_{3}\right)_{3}$ with $\mathrm{m} / \mathrm{z}=57$, all present in the spectrum. The corresponding stable gaseous species are $\mathrm{C}_{2} \mathrm{H}_{2} \mathrm{O}$ (ketene), $\mathrm{CH}_{3} \mathrm{CHO}$ (acetaldehyde) and $\mathrm{C}_{4} \mathrm{H}_{8}$ (2-methyl propene, or isobutene). $\mathrm{CO}$ is probable from the fragmentation of $\mathrm{CHCO}$ and/or $\mathrm{CH}_{3} \mathrm{CO}$, though the $\mathrm{m} / \mathrm{z}$ value of $\mathrm{CO}$ is too low to have been detected by the mass spectrometer employed in the present study.

As the vapour pressure of the subliming solid precursor is rather low (Wolf et al 1972), a rather high flow rate of
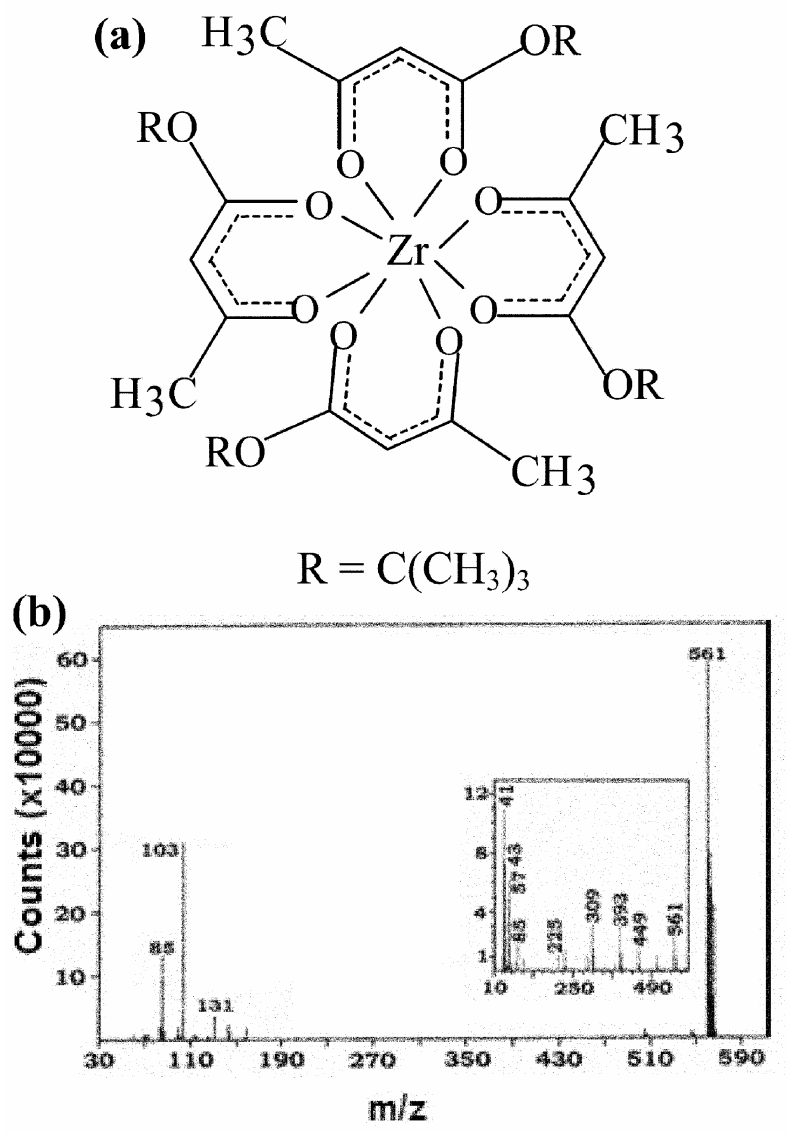

Figure 1. (a) Molecular structure of $\mathrm{Zr}(\mathrm{tbob})_{4}\left[\mathrm{R}=\mathrm{C}\left(\mathrm{CH}_{3}\right)_{3}\right]$ and (b) electron-impact (EI) mass spectrum of $\mathrm{Zr}(\mathrm{tbob})_{4}$, recorded on a JEOL mass spectrometer using an ionization potential of $70 \mathrm{eV}$. the (inert) carrier gas is generally needed to carry sufficient precursor vapour to the reaction chamber. So, the probability of reactions between precursor fragments is low; but the fragments undergo collisions and reactions with the molecules of the reactant gas, viz. oxygen. The fragments may then be expected to be partially or fully oxidized. The hydrocarbons are expected to produce $\mathrm{CO}_{2}$ and water vapour. $\mathrm{CO}$ and $\mathrm{CO}_{2}$ are expected from carbon. Different organic acids are expected from the total or partial oxidation of acetaldehyde and ketene. Every possible solid product is considered for the analytical study, and is listed in table 1 along with the possible gaseous products, as argued above.

Calculations were performed, as described earlier (Mukhopadhyay et al 2002) to predict the concentrations of the various solid and gaseous products of the MOCVD process, as functions of substrate temperature $\left(T_{\mathrm{sub}}\right)$, total reactor pressure $(P)$, and the ratio of the molar flow rates of oxygen and precursor vapour $\left(\mathrm{O}_{2} /\right.$ pre $)$. The corresponding phase stability diagram was also constructed.

\subsection{Experimental}

The zirconium complex was synthesized, purified and characterized in house (Urs et al 2003). This metalorganic complex, which sublimes at $\sim 150^{\circ} \mathrm{C}$, is relatively unreactive to air and moisture and may, therefore, be stored and utilized without special arrangements. Zirconium dioxide thin films were grown in a hot-wall, horizontal, low-pressure MOCVD reactor, in which the total pressure $(P)$, flow rates of carrier and reactant gases, substrate temperature $\left(T_{\text {sub }}\right)$, and the precursor vapourizer temperature $\left(T_{\text {vap }}\right)$ could be controlled. The CVD conditions used for the depositions are listed in table 2. Further details of the CVD process are described elsewhere (Dharmaprakash and Shivashankar 2003a, b). The as-deposited films were characterized by X-ray diffraction (XRD) and transmission electron microscopy (TEM) for the identification of crystalline phases, and Auger electron spectroscopy (AES) for quantitative elemental analysis. The films of $\mathrm{ZrO}_{2}$ were characterized also by Fourier transform infrared (FTIR) spectroscopy.

\section{Results and discussion}

\subsection{Analytical}

An important variable in thermodynamic calculations is the relative molar concentrations of the reactants, i.e. molar flow rates of oxygen, and the metalorganic complex, in the present case. While this molar ratio, $\mathrm{O}_{2} /$ pre, may be varied over a wide range experimentally, there is an upper limit to the number of moles of oxygen that can be consumed by one mole of the precursor. This is the number of moles of oxygen required to oxidize all the constituent atomic spe- 
Table 1. The phases considered for the thermodynamic analysis of MOCVD in oxygen atmospheres.

\begin{tabular}{lcc}
\hline Atmosphere & Precursor & \multicolumn{1}{c}{ Phases } \\
\hline Oxygen & $\mathrm{Zr}(\text { tbob) })_{4}$ & Solid: $\mathrm{Zr}, \mathrm{ZrO}_{2},{\mathrm{ZrC}, \mathrm{ZrH}_{2}, \mathrm{C}}$ \\
& & Gas: $\mathrm{CO}, \mathrm{CO}_{2}, \mathrm{H}_{2} \mathrm{O}, \mathrm{C}_{4} \mathrm{H}_{8}$ (2-methyl propene, or isobutene), \\
& & $\mathrm{C}_{2} \mathrm{H}_{2} \mathrm{O}\left(\mathrm{ketene}_{2}, \mathrm{CH}_{3} \mathrm{CHO}\right.$ (acetaldehyde), HCOOH (formic acid), \\
& and $\mathrm{CH}_{3} \mathrm{COOH}$ (acetic acid) \\
\hline
\end{tabular}

Table 2. Range of CVD conditions used for the deposition of zirconia thin films

\begin{tabular}{ll}
\hline Precursor & $\mathrm{Zr}(\text { tbob })_{4}$ \\
Substrate temperature $\left(T_{\text {sub }}\right)$ & $400-700^{\circ} \mathrm{C}$ \\
Vapourizer temperature $\left(T_{\text {vap }}\right)$ & $200^{\circ} \mathrm{C}$ \\
Carrier gas $(\mathrm{Ar})$ flow rate $\left(F_{\mathrm{Ar}}\right)$ & $50 \mathrm{sccm}$ \\
Reactive gas $\left(\mathrm{O}_{2}\right)$ flow rate $\left(F_{\text {oxy }}\right)$ & $50 \mathrm{sccm}$ \\
Total reactor pressure $(P)$ & $2 \mathrm{Torr}$ \\
Deposition time & $90 \mathrm{~min}$ \\
Substrates & $\mathrm{Si}(100)$, glass \\
\hline
\end{tabular}

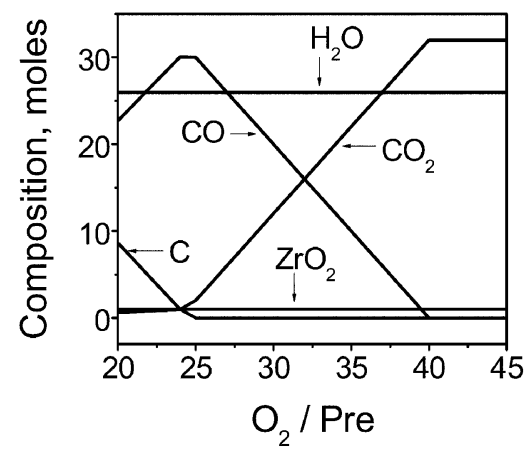

Figure 2. Variations in the calculated equilibrium molar concentrations of various condensed and gaseous phases as a function of $\mathrm{O}_{2} /$ pre at $T_{\text {sub }}=575^{\circ} \mathrm{C}$ and $P=2$ Torr

cies completely. This limit is 40 for $\mathrm{Zr}(\mathrm{tbob})_{4}$, based on the assumption of complete oxidation of $\mathrm{Zr}, \mathrm{C}$ and $\mathrm{H}$ to $\mathrm{ZrO}_{2}, \mathrm{CO}_{2}$ and $\mathrm{H}_{2} \mathrm{O}$, respectively. Any oxygen beyond this limit does not affect the thermodynamic calculations. The range of $\mathrm{O}_{2} /$ pre ratios used in the present analysis is close to this upper limit, this being the range required for the experimental deposition process. The theoretically determined solid phases in this range are pure $\mathrm{ZrO}_{2}$ and $\mathrm{ZrO}_{2}$ deposited simultaneously with carbon. Monoclinic zirconia, being most stable in the bulk state for the temperature range studied, is the polymorph predicted in the thermodynamic calculations, as is graphitic carbon. Correspondingly, $\mathrm{CO}, \mathrm{CO}_{2}$ and water vapour are formed in the gas phase, according to these calculations, signifying that all the organic fragments will have been oxidized into these vapours, prior to forming any other stable product.

Figure 2 shows variations in the calculated equilibrium molar concentrations of the various condensed and gaseous phases, as functions of $\mathrm{O}_{2} /$ pre, at $T_{\text {sub }}=575^{\circ} \mathrm{C}$ and
$P=2$ Torr. It was assumed that one mole of the precursor is consumed (If the amount of precursor consumed is different, the numbers on the ordinate of figure 2 will be altered merely by a multiplication factor, the relative proportions of the compounds formed remaining the same). It can be inferred from the figure that a significant amount of carbon is deposited along with $\mathrm{ZrO}_{2}$. The proportion of carbon decreases with increasing $\mathrm{O}_{2}$ /pre ratio, while that of gaseous $\mathrm{CO}$ and $\mathrm{CO}_{2}$ increases, each at a different rate. As the amount of carbon falls to zero, the proportion of $\mathrm{CO}$ decreases steadily, producing $\mathrm{CO}_{2}$, until all the carbon present in the precursor is oxidized to form $\mathrm{CO}_{2}$.

Similar calculations were performed as a function of temperature, at $P=2$ Torr, for two different $\mathrm{O}_{2} /$ pre ratios. The lower ratio $\left(\mathrm{O}_{2} /\right.$ pre $\left.=22\right)$ represents a regime wherein a significant amount of carbon is expected to be deposited along with $\mathrm{ZrO}_{2}$ throughout the temperature range considered, as indicated in figure 3(a). For the higher value of $\mathrm{O}_{2} /$ pre, carbon-free pure $\mathrm{ZrO}_{2}$ is expected at a temperature within the range of calculations. Thus, when $\mathrm{O}_{2} /$ pre $=25$, the amount of carbon reduces to zero at $550^{\circ} \mathrm{C}$ and above, as shown in figure $3(\mathrm{~b})$.

The corresponding 'CVD phase stability diagram' for the formation of the solid phases is presented in figure 4, indicating the stability windows for the formation of pure zirconia, and simultaneously deposited zirconia/carbon, at $P=2$ Torr. The $\mathrm{O}_{2} /$ pre ratio required for the elimination of carbon from the deposit decreases as the temperature is increased. That is, the process window for the deposition of carbon-free pure $\mathrm{ZrO}_{2}$ films becomes wider at higher deposition temperatures.

\subsection{Experimental}

MOCVD runs were carried out using process parameters spanning the range suggested by thermodynamic analysis. The ranges of substrate temperature and total reactor pressure required for measurable deposition were consistent with thermodynamic analysis, while the $\mathrm{O}_{2} /$ pre ratio had to be raised above the theoretically suggested value to obtain films without much carbon impurity. This discrepancy may be due to kinetic factors, such as the relative sticking probabilities of the molecules of oxygen and the precursor on the substrate (Kang et al 2000). The need for, and the degree of higher $\mathrm{O}_{2}$ /pre ratio required may depend in part on hydrodynamics, i.e. the specific design of the reactor. 
Figure 5 shows the XRD patterns of the films on $\mathrm{Si}(100)$ substrates deposited at different temperatures. Crystalline films comprising mainly of cubic $\mathrm{ZrO}_{2}$ were obtained up to $575^{\circ} \mathrm{C}$. Above this temperature, monoclinic $\mathrm{ZrO}_{2}$ was deposited, along with the cubic phase. TEM analysis of a $\mathrm{ZrO}_{2}$ film, grown on glass at $500^{\circ} \mathrm{C}$, also reveals the crystalline cubic phase (figure 6). Although thermodynami-
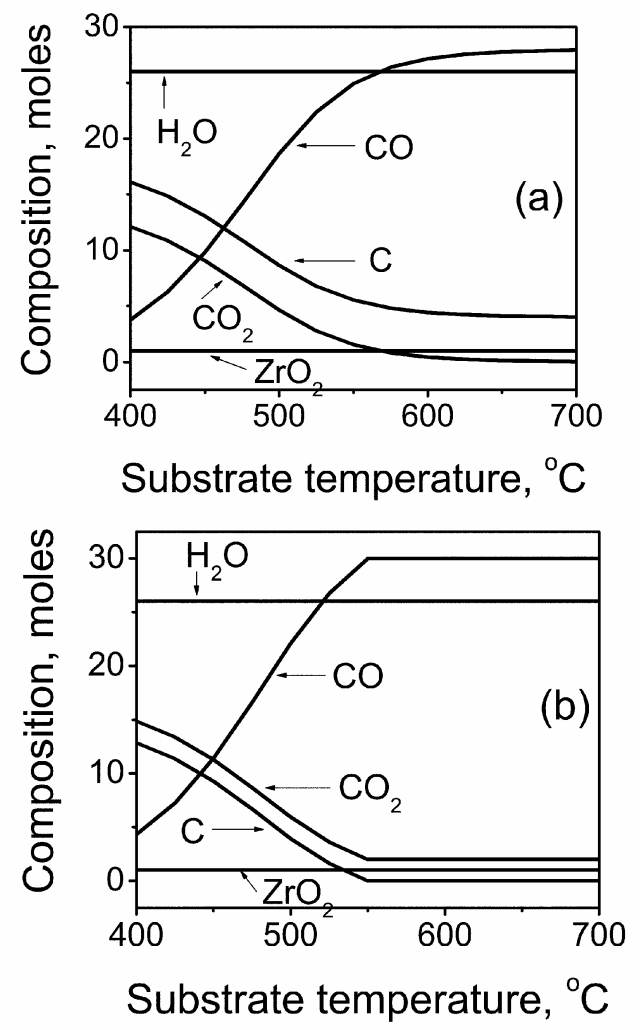

Figure 3. Variations in the calculated equilibrium molar concentrations of various condensed and gaseous phases as a function of substrate temperature, $T_{\text {sub }}$, at $P=2$ Torr and $\mathrm{O}_{2} /$ pre $=$ (a) 22 and (b) 25 . Note that proportionately less $\mathrm{C}$ than $\mathrm{CO}_{2}$ is produced when $\mathrm{O}_{2} /$ pre increases.

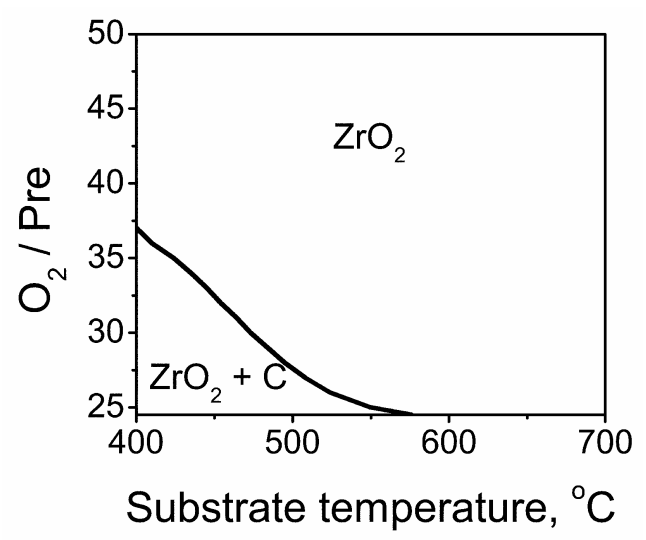

Figure 4. 'CVD phase stability diagram' to represent the formation of solid phases from $\mathrm{Zr}(\mathrm{tbob})_{4}$ and $\mathrm{O}_{2}$ at $P=2$ Torr. cally stable monoclinic zirconia is expected to form under deposition conditions employed here, there are indeed a number of reports showing that under CVD conditions, usually below $1000^{\circ} \mathrm{C}$, cubic or tetragonal zirconia is formed (Morozova et al 1993; Kim et al 1995; Kytokivi et al 1996; Bourhila et al 1997; Colombo et al 1998). This may be understood on the basis that CVD conditions affect the nucleation and growth of zirconia films by influencing the decomposition and reaction pathways, thus promoting different polymorphs. Various factors determine the crystalline phase of $\mathrm{ZrO}_{2}$ films deposited, including substrate temperature, critical crystal size, film thickness, and the CVD precursor employed (Putkonen and Niinisto 2001). The exclusive formation of cubic zirconia below $575^{\circ} \mathrm{C}$ in the present work may be explained in terms of the crystallite-size effect, driven by the lower surface free energy of the cubic phase (Morstein et al 1999). Barnard et al (2006) investigated this effect by applying a thermodynamic model based on the free energy of nanocrystals as a function of size and shape.

MOCVD runs conducted at relatively low temperatures $\left(T_{\text {sub }}<500^{\circ} \mathrm{C}\right)$, led to the deposition of blackish, carbonaceous films which were X-ray amorphous. Yet, the films contained $\mathrm{ZrO}_{2}$, as confirmed by FTIR spectroscopy (figure 7). The bands at $415 \mathrm{~cm}^{-1}, 435 \mathrm{~cm}^{-1}, 532 \mathrm{~cm}^{1}$ and $658 \mathrm{~cm}^{-1}$ correspond to various vibrations of the $\mathrm{Zr}-\mathrm{O}$ bond (Ismail et al 1990). We surmise that the large proportion of carbon in the deposits obtained under these conditions limits the mobility of the oxide forming species, making the oxide X-ray amorphous. It is to be noted that the FTIR spectra contain no features attributable to carbonate or hydroxide formation, even though the films were stored in the laboratory ambient. Just as important, the absence in these spectra of different bands corresponding to the $\mathrm{C}=\mathrm{C}, \mathrm{C}=\mathrm{O}$ and $\mathrm{C}-\mathrm{H}$ bond stretching, even in films deposited at $400^{\circ} \mathrm{C}$, confirms that the $\mathrm{Zr}-\mathrm{O}$

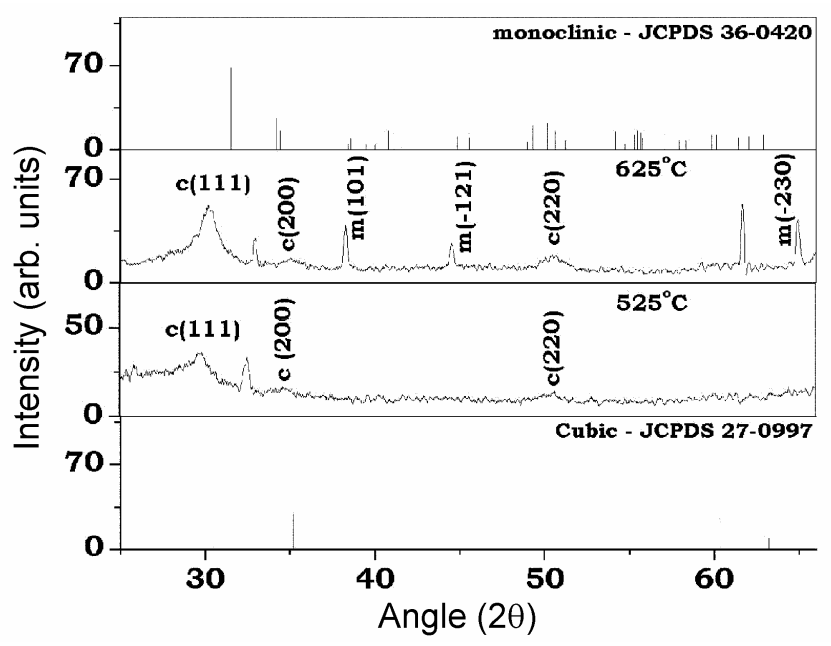

Figure 5. $\mathrm{XRD}$ of $\mathrm{ZrO}_{2}$ thin films on $\mathrm{Si}(100)$ substrates grown at different temperatures. 

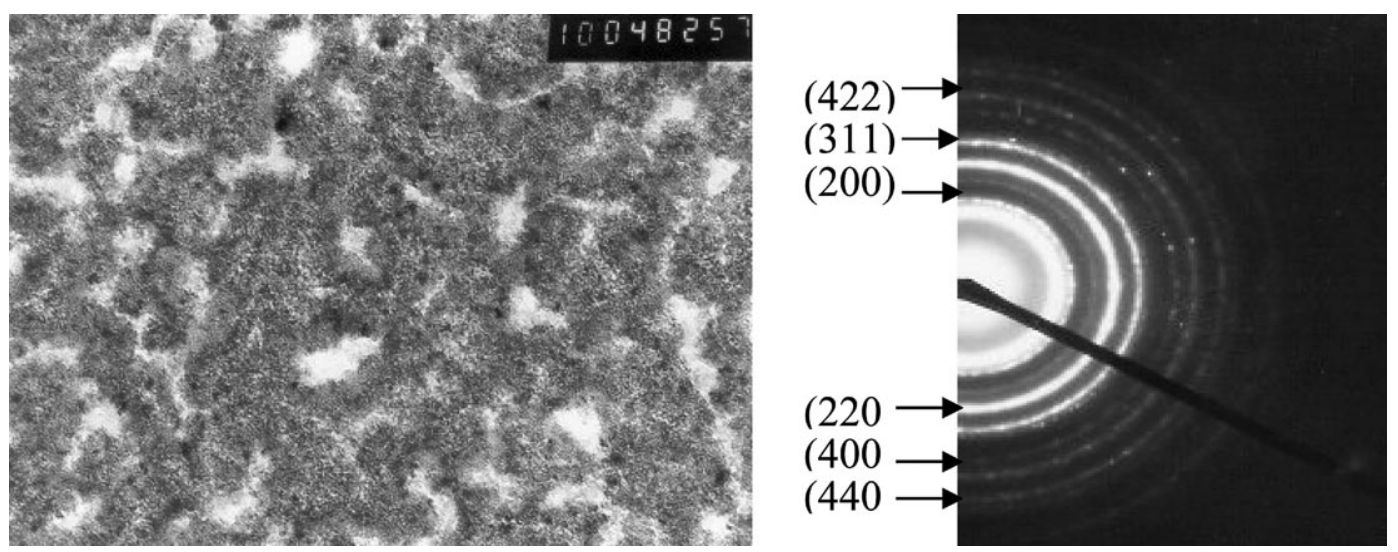

Figure 6. TEM of $\mathrm{ZrO}_{2}$ thin films deposited on glass at $500^{\circ} \mathrm{C}$.
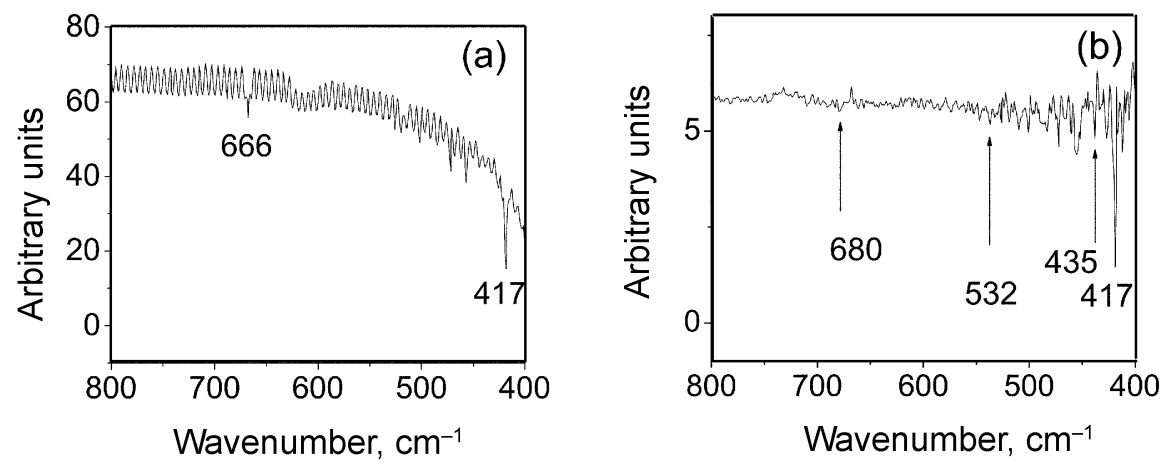

Figure 7. FTIR of $\mathrm{ZrO}_{2}$ thin films deposited at (a) $400^{\circ} \mathrm{C}$ and (b) $475^{\circ} \mathrm{C}$.

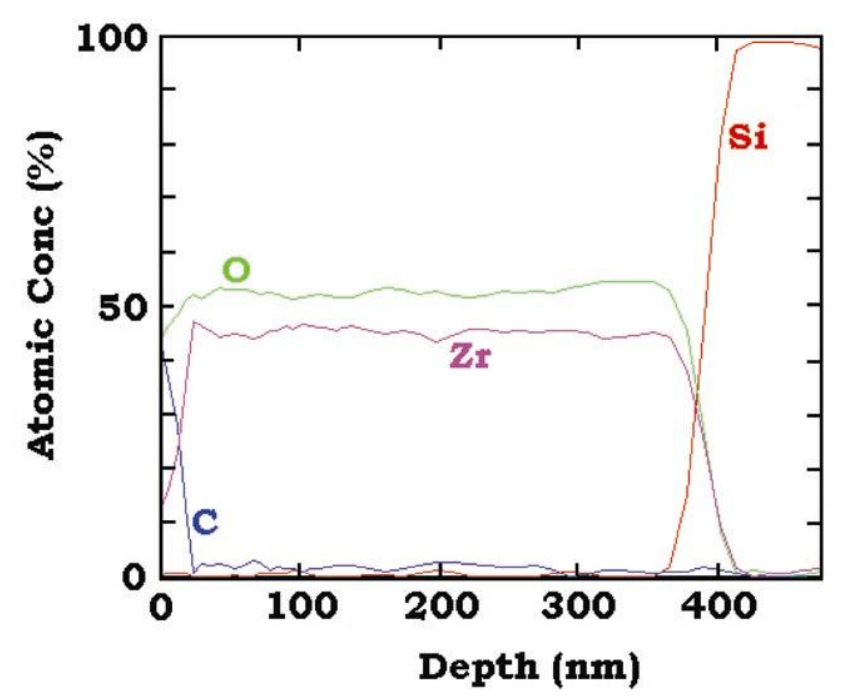

Figure 8. AES depth profile of $\mathrm{ZrO}_{2}$ thin film grown on $\mathrm{Si}(100)$ at $575^{\circ} \mathrm{C}$.

vibrations recorded are not due to the undecomposed precursor, but due to the formation of $\mathrm{ZrO}_{2}$. These findings are in agreement with thermodynamic calculations (figure 4).
To examine film composition and the presence, if any, of chemical impurities, the AES depth profile of a film grown at $575^{\circ} \mathrm{C}$ was obtained (figure 8 ). The data show that the $\mathrm{ZrO}_{2}$ films are sub-stoichiometric, containing considerably less oxygen $(\mathrm{O} / \mathrm{Zr}=\sim 1 \cdot 2)$ than indicated by the chemical formula of $\mathrm{ZrO}_{2}$. This is not surprising, as sub- or super-stoichiometric metal oxide films have often been obtained by MOCVD (Jones et al 1998; Smith et al 2000). Further, the AES data reveal that the extent of carbon incorporation in the bulk of the film, stemming from the precursor itself, is less than 5\%. This supports the FTIR data, which contains no evidence of bands due to $\mathrm{C}-\mathrm{C}$ or $\mathrm{C}-\mathrm{O}$ bonds. The presence of a residual amount of carbon may be interpreted as reflecting the inability of thermodynamic modeling to take reaction kinetics into account.

\section{Conclusions}

Through a thermodynamic analysis of the MOCVD of zirconia films, the equilibrium compositions of the solid ( $\mathrm{ZrO}_{2}$ and $\mathrm{ZrO}_{2} /$ carbon) and gaseous species formed during the process were calculated, and the corresponding 
CVD phase stability diagram constructed. Experimental depositions were conducted for the growth of $\mathrm{ZrO}_{2}$ films, using CVD parameters suggested by the analysis. XRD, TEM and FTIR data confirm the formation of $\mathrm{ZrO}_{2}$ films. Monoclinic zirconia, being most stable in the bulk state for the temperature range studied, is predicted by thermodynamic calculations, but CVD process conditions promote different polymorphs.

The AES data on films deposited suggest that the removal of carbon is not as complete as the thermodynamic calculations predict. The presence of residual amounts of carbon may be interpreted as reflecting the inability of thermodynamic modeling to take reaction kinetics into account. Despite this limitation, thermodynamic analysis of CVD processes may be used to determine the range of thermodynamic process parameters needed to obtain films of the desired composition and quality.

\section{Acknowledgements}

The authors thank Pritesh Dagur for the FTIR data. The AES analysis provided by Venkatashamy Reddy is gratefully acknowledged. One of the authors (SD) thanks the DST, Government of India, for the grant of a research fellowship.

\section{References}

Barnard A S, Yeredla R R and Xu H 2006 Nanotechnology 17 3039

Bernard C, Pons M, Blanquet E and Madar R 1999 MRS Bull. 2427

Bourhila N, Felten F, Senateur J P, Schuster F, Madar R and Abrutis A 1997 Proc. Electrochem. Soc. 25417
Colombo D G, Gilmer D C, Young Jr V G, Campbell S A and Gladfelter W L 1998 Chem. Vapor Depos. 4220

Dharmaprakash M S and Shivashankar S A 2003a Mater. Res. Soc. Symp. Proc. 745191

Dharmaprakash M S and Shivashankar S A 2003b Proc. Electrochem. Soc. PV8 900

Eriksson G 1971 Acta Chem. Scand. 25651

Huang S S and Wu T B 2004 J. Vac. Sci. Technol. B22 1940

Ismail M G M U, Tsunatori H and Nakai Z $1990 \mathrm{~J}$. Am. Ceram. Soc. 73537

Jones A C et al 1998 Chem. Vapor Depos. 446

Kang S Y, Choi K H, Lee S K, Hwang C S and Kim H J $2000 \mathrm{~J}$. Electrochem. Soc. 1471161

Kim J S, Marzouk H A and Reucroft P J 1995 Thin Solid Films 25433

Kytokivi A, Lakomaa E L and Root A 1996 Langmuir 124395

Li W, Liu X, Huang A and Chu P K 2007 J. Phys. D: Appl. Phys. 402293

Lin J M, Hsu M C and Fung K Z 2006 J. Power Sources 159 49

Morozova N B, Igumenov I K, Yushina I V, Ayupov B M and Lisoivan V I 1993 Inorg. Mater. 29949

Morstein M, Pozsgai I and Spencer N D 1999 Chem. Vapor Depos. 5151

Mukhopadhyay S, Shalini K, Lakshmi R, Devi A and Shivashankar S A 2002 Surf. Coat. Technol. 150205

Pasko S V, Abrutis A and Hubert-Pfalzgraf L G 2004 Mater. Lett. 59261

Patil U et al 2006 Chem. Vapor Depos. 12172

Putkonen M and Niinisto L 2001 J. Mater. Chem. 113141

Smith R C et al 2000 Adv. Mater. Opt. Electron. 10105

Stringfellow G B 1989 Organometallic vapour phase epitaxytheory and practice (New York: Academic Press) Ch. 3

Urs U K, Dharmaprakash M S, Shivashankar S A and Row T N G 2003 Acta Crystallogr. E59 m83

Wolf W C, Sievers R E and Brown G H 1972 Inorg. Chem. 11 1995 